\title{
Identidade Territorial e Agricultura Familiar no Município de Rolim de Moura (RO)
}

\author{
Edson Aparecida Araujo Querido Oliveira \\ Universidade de Taubaté \\ Maria Antonia Fernandes Nabarro de Oliveira Benati \\ Universidade de Taubaté e Faculdade São Paulo \\ Marcela Barbosa de Moraes \\ Universidade de Taubaté
}

\section{Resumo}

O objetivo deste estudo é compreender a contribuição da agricultura familiar como fomentadora da formação de uma identidade territorial na cidade de Rolim de Moura (RO). A pesquisa é descritiva exploratória e, quanto à abordagem, é quantitativa. Para a coleta dos dados foram aplicadas 321 entrevistas estruturadas, por meio de formulários, a agricultores familiares da área de estudo no período entre 4 de fevereiro e 2 de março de 2017. Os dados coletados foram dispostos em tabelas e correlacionados utilizando-se a correlação de Pearson; dentre as correlações foram destacadas a de maior significância que nortearam a descrição dos resultados. Os resultados encontrados apontaram que no Município de Rolim de Moura (RO) os agricultores familiares dependem da renda da propriedade rural para seu sustento e que as relações com a terra estão além dos conceitos de território geográfico, envolvendo questões simbólicas, sociopolíticas e econômicas que podem contribuir para o desenvolvimento local e criar uma identidade territorial para o Município de Rolim de Moura (RO).

Palavras-chave: Gestão. Desenvolvimento Regional. Agricultura Familiar. Identidade Territorial.

\section{Territorial Identity and Family Agriculture in the Municipality of Rolim de Moura}

(RO)

\footnotetext{
Abstract

The aim of this study is to understand the contribution of family agriculture as a sponsor of the formation of a territorial identity in the city of Rolim de Moura (RO). The research is descriptive exploratory and, as far as the approach is concerned, it is quantitative. For the data collection, 321 interviews were applied, structured through forms, to family farmers in
} 
the study area in the period between February 4 and March 2, 2017. The data collected were arranged in tables and correlated using the correlation of Pearson; among the correlations were highlighted the one of greater significance that guided the description of the results. The results showed that in the municipality of Rolim de Moura (RO), family farmers depend on the income of rural property for their livelihoods and that land relations are beyond the concepts of geographic territory, involving symbolic, socio-political and economic issues that can contribute to local development and create a territorial identity for the municipality of Rolim de Moura (RO).

Keywords: Management. Regional Development. Family Agriculture. Territorial Identity.

\section{Identidad Territorial y Agricultura Familiar en el Municipio de Rolin de Moura (RO)}

\section{Resumen}

El objetivo de este estudio es comprender la contribución de la agricultura familiar como fomentadora de la formación de una identidad territorial en la ciudad de Rolim de Moura (RO). La investigación es descriptiva exploratoria y, en cuanto al abordaje, es cuantitativa. Para la recolección de los datos se aplicaron 321 entrevistas estructuradas a través de formularios a agricultores familiares del área de estudio en el período entre el 4 de febrero y el 2 de marzo de 2017. Los datos recolectados fueron dispuestos en tablas y correlacionados utilizando la correlación de Pearson; de las correlaciones fueron destacadas la de mayor significancia que orientaron la descripción de los resultados. Los resultados encontrados apuntan que en el Municipio de Rolim de Moura (RO) los agricultores familiares dependen del ingreso de la propiedad rural para su sustento y que las relaciones con la tierra están más allá de los conceptos de territorio geográfico, involucrando cuestiones simbólicas, sociopolíticas y económicas que pueden contribuir al desarrollo local y crear una identidad territorial para el Municipio de Rolim de Moura (RO).

Palabras clave: Gestión. Desarrollo Regional. Agricultura Familiar. Identidad territorial.

\section{Introdução}

A agricultura familiar brasileira dispõe de ampla diversidade social, econômica e cultural, variando desde a pastoril tradicional até a pequena produção modernizada. Há uma pluralidade de estratégias de desempenho da agricultura familiar no domínio da economia territorial, o que beneficia o planejamento e a administração dos recursos naturais, a organização mais igualitária e sua gestão mais descentralizada (NANTES; SCARPELLI, 2001).

Por muito tempo intitulada agricultura de subsistência, a agricultura familiar faz parte da rotina das atividades produtivas do país e contribui para a atividade econômica e o desenvolvimento das regiões, consequentemente influenciando na identidade econômica, cultural e social dos recortes geográficos (ABRAMOVAY, 2006).

O município de Rolim de Moura, localizado na região da Zona da Mata Vale do Guaporé (RO), é um importante polo regional, e o município mais populoso e economicamente ativo da Zona da Mata rondoniense. A população, segundo dados do Censo do IBGE (2010), é de 50.648 habitantes e a área é de $1.458 \mathrm{~km}^{2}$, localizada a $476 \mathrm{~km}$ de Porto Velho, capital de Rondônia, seguindo o trajeto pela BR-364. Teve sua emancipação político-administrativa efetivada pelo Decreto-Lei $N^{\circ} .071$ de 05 de agosto de 1983 e, sua instalação em 09 de novembro de 1984 (JANUÁRIO, 2012). 
De acordo com Censo Agropecuário de 2006, do total de habitantes menos de $20 \%$ da população do município habitava a zona rural. O PIB do município é de R\$ 792.969.881,00, justificando a sua posição de $7^{\circ}$ maior do Estado (IBGE, 2013).

A área plantada do município de Rolim de Moura (RO) é de 7.870 hectares (5,40\% de sua área total), distribuída entre os principais produtos produzidos: café, arroz, milho, feijão, mandioca e banana. A agricultura familiar exerce papel precursor na economia do município. Muitos migrantes se instalaram na zona rural na década de 1980, inserindo essas culturas (JANUÁRIO, 2012).

A pecuária de leite também apresentou importância preponderante na evolução histórica da economia de Rolim de Moura, e é considerada a segunda mais importante atividade econômica do município (IBGE, 2010).

Os agricultores ainda produziam hortifrutigranjeiros que nem sempre tinham comercialização garantida ou eram comercializados a preço muito baixo, ficando os agricultores e seus familiares, em sua maioria, à mercê dos preços que eram praticados pelos atravessadores e empresários do ramo de supermercados.

Diante dessas dificuldades e do êxodo rural dos descendentes dos agricultores familiares, o ocorrido ainda contribuiu para o aumento de problemas sociais, como distribuição de renda, desemprego e marginalidade, dentre outros (MATEUS, 2015).

A problemática deste estudo se volta à análise de como a agricultura familiar atua como fomentadora da economia, da cultura e da política do município de Rolim de Moura (RO), a partir da seguinte questão norteadora: Qual é a contribuição da agricultura familiar na criação da identidade territorial desse Município?

Haesbaert (1999) afirma que toda identidade territorial é uma identidade social definida por seu do território, ou seja, dentro de uma relação de apropriação que se dá tanto no campo das ideias quanto no da realidade concreta. Trata-se de uma identidade em que um dos aspectos fundamentais para sua estruturação está na referência de um território, tanto no sentido simbólico quanto no sentido concreto.

Assim, a importância de estudar a identidade territorial do município de Rolim de Moura (RO) não se restringe somente ao sentido relacional e sim nas interrelações entre os indivíduos com seus territórios e nas diversidades dessas áreas, que os definem como únicos e, assim, os constituem.

\section{Conceituando Território}

Abordado de forma introdutória nas ciências naturais, a compreensão de território indicava a associação entre a influência de espécies animais ou vegetais com uma determinada área física (SCHMITT; TURATTI; CARVALHO, 2002). Posteriormente, o embasamento teórico de território foi incorporado pela geografia, que associa recursos naturais, espaço, poder e sociedade. A seguir, disciplinas como sociologia, antropologia, economia e ciência política passaram a absorver o debate desses conceitos (FLORES, 2006).

O território foi escolhido por pesquisadores de diversas áreas do conhecimento como conceito central para o estudo de diferentes escalas e tipos de espaços geográficos e na elaboração de projetos de políticas públicas (MAGNAGHI, 
2014). Lastres e Cassiolato (2005) ressaltam que a palavra território em suas variações refere-se à apropriação ou domínio coletivo ou individual e atribuem as seguintes dimensões:

- física: refere-se aos recursos naturais e aos resultados dos usos e práticas territoriais dos grupos sociais;

- econômica: refere-se à organização dos processos de produção do recorte geográfico;

- sociopolíticas: refere-se às relações sociais de domínio e de poder;

- simbólica: refere-se às relações afetivas, culturais e de identidade do indivíduo ou grupo com o seu espaço; e

- cognitiva: refere-se às condições para geração, uso e difusão de conhecimentos.

Quanto às dimensões do território, Dallabrida (2000), Albagli (2004) e Fernandes (2013) atribuem a materialidade à dimensão física; a divisão territorial do trabalho e acumulação de capital à dimensão econômica; os conflitos e alianças entre grupos à dimensão sociopolítica; e a identidade coletiva de representações sociais à dimensão simbólica.

Haesbaert (2014) e Ribeiro (2015) afirmam que as intervenções territoriais inteligentes podem acontecer embasados em dois requisitos: a construção de um novo conhecimento e a construção do poder político local/regional.

Assim, atribui-se ao território o eixo para formulação de estratégias de desenvolvimento regional, que é objeto de influência da cultura da sociedade por meio de movimentos sociais, de entidades privadas e de organizações nãogovernamentais (BUARQUE, 2002; DALLABRIDA, 2007; BRENT, 2015).

Quanto ao desenvolvimento territorial, Albagli (2004) atribui às externalidades positivas decorrentes da proximidade, da cooperação e da organização dos atores sociais. Santos e Pontes (2016) afirmam que o território se constitui enquanto tal não por que é construído pelo homem apenas, mas por que tem um conteúdo político que passa pelas manifestações de poder do espaço, sintetizando o conflito de classes existente na sociedade.

Albagli (2004) reconhece que é possível determinar modelos que visam o fortalecimento das territorialidades pelo estímulo dos vínculos de similaridade e colaboração, fundamentados na conveniência comum de preservar, reconhecer e acumular o que um determinado território possui - seu patrimônio cultural, suas peculiaridades, suas técnicas produtivas, potencialidades econômicas e seus recursos ambientais.

Hoggart e Buller (2015) alertam para a improvável construção dessas territorialidades apoiadas nas condições externas, sem estar fundamentadas nos recursos socioculturais do território; e assegura que o reconhecimento baseado em interesses externos, de particularidade instrumental, propõe angariar investimentos.

Dessa forma, a territorialidade é valorizada apenas pelo interesse especulativo e comercial, causando a exploração da territorialidade como forma predatória e insustentável no longo prazo, propensa a destruição do meio ambiente e do capital social (ALBAGLI, 2004).

Albagli (2004) reconhece que é possível determinar modelos que visam o fortalecimento das territorialidades pelo estímulo dos vínculos de similaridade e 
Edson Aparecida Araujo Querido Oliveira, Maria Antonia Fernandes Nabarro de Oliveira Benati,

colaboração, fundamentados na conveniência comum de preservar, reconhecer e acumular o que um determinado território possui - seu patrimônio cultural, suas peculiaridades, suas técnicas produtivas, potencialidades econômicas e seus recursos ambientais.

\section{Conceitos sobre Identidade}

A identidade envolve diversos entendimentos, relacionando-se tanto ao indivíduo no âmbito pessoal, como também na relação do indivíduo com a coletividade (FROELICH, 2013). A categoria de análise de identidade surge em enfoques diferenciados, sujeitando-se à origem teórica na qual é abordada (FLORES, 2006).

A existência dos inúmeros princípios abordados no conceito de identidade é fruto da subdivisão do conhecimento, tendo em vista que o conceito de identidade é beneficiado nos estudos da Sociologia, Antropologia, História, Psicologia e Filosofia e, mais recentemente, na descrição da interação entre sociedade e espaço (LEBOSSÉ, 2004).

O entendimento de identidade é uma construção social, e ao longo do tempo os diferentes grupos sociais conceberam descrições que constroem identidades associadas a uma estipulada ideologia, etnia, cultura ou religião (BOLIGIAN, 2003).

Cherlotti e Pessôa (2010) julgam que a construção das identidades ocorre por meio das subjetividades individuais e coletivas, podendo relacionar-se a grupos sociais ou à afeição de pertencimento territorial, sendo que a dimensão simbólica do intangível na manifestação geográfica oportuniza as análises da produção do espaço, das paisagens e territorialidades.

A organização das identidades está consonante ao entendimento de imaterialidade, que permite uma análise dos sentimentos inclusos na técnica da construção da identidade e do investimento pessoal realizados em posições específicas de identidade (WOODWARD, 2009).

Gaio e Gouveia (2007) pressupõe que a identidade é um conceito emissor, que remete para um fenômeno dinâmico entre a dimensão política, os tangíveis territoriais e os resultados das interações sociais, económicas, tecnológicas das pessoas no espaço, que constituem a base dos processos de construção de imagem dos territórios, por meio da sua dimensão funcional e simbólica.

Giddens (2002) sugere que a identidade oculta negociações de sentido, choques de interesse, processos de diferenciação e hierarquização das diferenças, configurando como estratégia sutil de regulação das relações de poder.

Sawaia (2001) afirma que identidade é conceito político ligado ao processo de inserção social em sociedades complexas, hierarquizadas e exclusivas, bem como ao processo de inserção social.

Para Doria (2002, p. 126),

[...] a identidade deve ser necessariamente interpretada como guia da ação projetual, como marca profunda da ação criativa, capaz de garantir senão uma hierarquia no universo aberto dos espaços projetuais, uma orientação naquela mobilidade particular que é própria do movimento de produção indefinida de alternativas (DORIA, 2002, p. 126). 
A identidade apresenta uma variabilidade elevada em termos tanto temporais quanto espaciais; antes, tal variabilidade tende a ser maior na dimensão temporal do que aquela espacial (HAESBAERT, 2014).

\section{Conceituando Identidade Territorial}

O conceito de identidade territorial faz parte dos argumentos de análise dos recortes geográficos. A relevância desses estudos conduz à capacidade explicativa de fenômenos amplos e diversificados (POLLICE, 2012).

Sawaia (2001) explica que a caracterização da identidade territorial ocorre por meio de uma natureza processual e interativa; considerando o resultado dos processos e mecanismos de interação entre as causas e efeitos das dinâmicas territoriais e da interatividade por sua capacidade intrínseca de entrar em relação sinérgica com outras ocorrências territoriais.

Seria oportuno, então, supor a identidade territorial não somente no sentido relacional, não apenas compreendendo que as identidades são consequências das inter-relações entre os indivíduos com seus territórios (HAESBAERT; LIMONAD, 2007).

De acordo com a visão de Lastres e Cassiolato (2005), Pollice (2012) e Helmsing (2016), o sentido de pertença dos atores sociais é um dos fatores que contribuem para o desenvolvimento local, ao compreender que o sentido relacional desses atores está relacionado com fatores sentimentais, sociais e simbólicos. Contribuindo, Haesbaert (2014) afirma que a identidade territorial não pode ser identicada nos objetos que a expressam: natureza, função e localização, mas deve ser baseada na atribuição de um valor simbólico da cultura ou do cenário.

Haesbaert (1999, p. 72) afirma que

[...] toda identidade territorial é uma identidade social definida fundamentalmente por meio do território, ou seja, dentro de uma relação de apropriação que se dá tanto nos campos das ideias quanto no da realidade concreta, o espaço geográfico constituindo assim parte fundamental dos processos de identificação social (HAESBAERT, 1999, p. 72).

\section{Agricultura Familiar: Valorização Territorial e Desenvolvimento Regional}

O desenvolvimento brasileiro, pela diversificação de seu sistema urbano, vai exigir uma nova dinâmica territorial em que o papel das unidades familiares pode ser decisivo (ABRAMOVAY, 2006).

Como exemplo, os autores Lang, Fink e Kibler (2014) afirmam que o sucesso de certas regiões rurais dos países desenvolvidos na geração de ocupações produtivas não pode ser atribuído a uma composição setorial favorável.

Segundo Lang, Fink e Kibler (2014, p. 207),

[...] os bons desempenhos na criação de empregos resultam de uma dinâmica territorial específica que ainda não é bem compreendida, mas que comporta provavelmente aspectos como a identidade regional, um clima favorável ao espírito empreendedor, à existência de redes públicas 
Edson Aparecida Araujo Querido Oliveira, Maria Antonia Fernandes Nabarro de Oliveira Benati,

e privadas ou a atração do meio ambiente cultural e natural (LANG; FINK e KIBLER, 2014, p. 207).

A exploração dessa nova dinâmica territorial supõe valorização territorial e o estímulo à formulação descentralizada de projetos capazes de valorizar os atributos locais e regionais no processo de desenvolvimento (CAMARGO; MEDINA, 2016).

Furtado (2004) afirma que no caso brasileiro a estrutura agrária é o principal fator que causa a extremada concentração da renda. Não tanto por que a renda seja mais concentrada no setor agrícola do que no conjunto das atividades produtivas, mas por que não havendo no campo praticamente nenhuma possibilidade de melhoria das condições de vida, a população rural tende a se deslocar para as zonas urbanas, congestionando a oferta de mão de obra não especializada.

Apesar dos expressivos avanços sociais dos últimos anos, a combinação de pobreza e desigualdade social no Brasil permanece como um dos desafios a serem enfrentados em uma estratégia de desenvolvimento. A recuperação econômica do país a partir de 2004 e o consequente aumento de recursos dos programas de transferência de renda propiciaram uma queda dessa desigualdade particularmente em termos de renda, mas os índices continuam preocupantes (BARROS, 2007).

O fator determinante para os elevados níveis de pobreza do país reside na estrutura da desigualdade brasileira, que se caracteriza em uma impiedosa desigualdade na distribuição da renda e das oportunidades de inclusão social.

Barros (2007) afirma ainda que o Brasil não é um país pobre, mas sim um país de muitos pobres, fato pelo qual destacou que a desigualdade social impede a valorização territorial e, por consequência, o desenvolvimento das regiões. De acordo com o autor, a pobreza no Brasil é um problema relacionado à distribuição dos recursos e não à sua escassez, e que amenizando as desigualdades sociais será possível combinar fatores que resultem na valorização dos territórios.

Gafsi (2014) supõe que a redução da desigualdade poderia ser apreciável para a massa de população em inferior condição de vida. Essa condição ocorreria pelo valor de bem viver de uma coletividade mais igualitária e porque a igualdade é o caminho mais factível para se erradicar situações moralmente inadmissíveis em um país de recursos fartos, como é o caso da miséria no Brasil.

Sen (2010) conceitua o desenvolvimento como um processo integrado de expansão de liberdades reais que as pessoas desfrutam, como a participação política. Apesar de reputar a importância das rendas individuais, esses aspectos aparecem como meios de expansão de liberdades, que também dependem de determinantes como o arranjo social e econômico e os direitos civis. Tal modelo de avaliação da conquista de uma sociedade distingue-se do modelo de avaliação mais tradicional, que se foca apenas em variáveis como renda real.

Quanto ao desenvolvimento, Bresser-Pereira (2006) conclui que:

o que é importante, em relação a esse problema, é ter claro que o desenvolvimento econômico é apenas um dos objetivos políticos das sociedades modernas, e, portanto, que há outros tão ou mais importantes que ele como a liberdade, a paz ou a segurança, a justiça social, e a proteção da natureza (BRESSER-PEREIRA, 2006, p.75).

Furtado (2004) afirma que o desenvolvimento não é apenas um processo de acumulação e de aumento de produtividade macroeconômica, mas principalmente 
o caminho de acesso a formas sociais mais aptas a estimular a criatividade humana e responder às aspirações da coletividade.

Para Brandão (2012), é a justiça territorial na construção de cidadania e nas potenciais e efetivas inversões de capital produtivo, com alto potencial e qualidade de geração de encadeamentos intersetoriais, impostos, empregos e divisas.

Torna-se desafiador discutir e orientar a implementação de políticas públicas que busquem colocar as forças inovativas e produtivas regionais a serviço do desenvolvimento sustentado, social e soberano, mas o próprio Estado precisa ser reaparelhado para fazer frente e contra restar os interesses conservadores e cosmopolitas que conspiram contra a definição de um projeto nacional de desenvolvimento (GAFSI, 2014).

Os dispositivos para o estímulo do desenvolvimento dos territórios devem ser orientados à evolução de suas partes constitutivas, objetivando o fortalecimento das condições da iminência cognitiva (MEDINA; NOVAES; TEIXEIRA, 2017).

Nesse contexto, Dallabrida (2013) discorre sobre governança territorial e gestão social onde a decisão se dá com base no entendimento e não na negociação, cuja finalidade é o bem comum. O autor caracteriza a Gestão Social como: tomada de decisão coletiva, sem coerção, com transparência, entendimento e autonomia; e caracteriza Governança Territorial como ...

[...] um processo de planejamento e gestão de dinâmicas territoriais, priorizando uma ótica inovadora, partilhada, colaborativa e relações não hierárquicas, em associação entre Estado, entidades sindicais, associações empresariais, centros universitários e de investigação, municípios e representações da sociedade civil, fundamentado num papel insubstituível do Estado, numa concepção qualificada de democracia e num maior protagonismo da sociedade civil, objetivando acordar uma visão compartilhada para o futuro e o desenvolvimento territorial (DALLABRIDA, 2013, p.329-330).

Basso et al. (2003) asseguram que a constituição de uma representação analítica que tenha como objetivo primordial a avaliação da capacidade produtiva das famílias rurais, na perspectiva da redução da pobreza e das desigualdades sociais, deve contemplar pelo menos três elementos centrais:

- os diversos ativos que essas famílias utilizam para garantir sua sobrevivência;

- os meios pelos quais os grupos familiares rurais são capazes de acessar, defender e manter seus ativos; e

- a capacidade de transformação destes ativos pelos grupos familiares em renda, dignidade, poder e sustentabilidade.

Os autores concluem que, a eficiência desses elementos centrais é o sustentáculo para a valorização e o desenvolvimento dos territórios.

O desenvolvimento dos territórios é tratado como o desenvolvimento local endógeno ou de dinâmica endógena pela qual a comunidade se torna capaz de se tornar o agente de seu desenvolvimento, capaz de equilibrar e transformar os agentes externos (LANDEL; PECQUEUR, 2016). 
Edson Aparecida Araujo Querido Oliveira, Maria Antonia Fernandes Nabarro de Oliveira Benati, Marcela Barbosa de Moraes

\section{Identidade Territorial e Desenvolvimento Regional por meio da Agricultura Familiar}

Para o alcance do desenvolvimento regional é necessária a compreensão do conceito e das características de desenvolvimento e nas menções de BresserPereira (2006, p. 32), "o desenvolvimento econômico de um país ou estados-nação é o processo de acumulação de capital e incorporação de progresso técnico ao trabalho e ao capital que leva ao aumento da produtividade, dos salários, e do padrão médio de vida da população".

Vieira e Santos (2013) entendem que o desenvolvimento é distinto do crescimento econômico, pois implica superação das assimetrias sociais e econômicas que reproduzem os processos de exclusão social.

Como o desenvolvimento econômico de um país depende do desenvolvimento de suas regiões respeitando suas limitações e peculiaridades e valorizando suas riquezas, o desenvolvimento regional é de fundamental importância para a constituição de uma nação fortalecida (BRESSER-PEREIRA, 2006).

Carniello e Oliveira (2010) entendem a região como espaços de vida, um produto socialmente constituído pela sociedade que independentemente de seu tamanho pode ser subdividido em várias partes.

A partir de meados do século $X X$, o estudo da economia regional tornou-se relevante por considerar o crescimento diferenciado das regiões uma preocupação para a sociedade na busca pela identidade regional, principalmente nos Estados Unidos e na Europa (CARNIELLO; OLIVEIRA, 2010).

Para a compreensão da identidade regional é necessária uma abordagem que ressalte o desempenho da sociedade como ator social na participação do processo de elaboração e consolidação do desenvolvimento.

Os autores afirmam que uma região com identidade facilita a criação de acordos básicos e a torna mais competitiva entre os agentes sociais. A ausência de identidade acarreta a carência do papel social das regiões, que passam a ser consideradas meros territórios fortuitos, absorvendo perdas de ações eficientes no planejamento regional.

Vernières (2014) afirma que o desenvolvimento exerce seu papel na promoção do método para a melhoria da qualidade de vida da população de um país, de uma região ou de um local específico.

O desenvolvimento está ligado à concepção de transformação dos procedimentos produtivos, tornando-os mais eficientes na geração de riqueza (CARNIELLO; OLIVEIRA, 2010).

Dentre as estratégias de intervenção para o desenvolvimento do território, Xavier et al (2014) destacam os espaços com características e condições que justifiquem investimento no contexto de uma realidade socioeconômica com recursos escassos; organização e capacitação dos atores sociais para participar do processo de construção coletiva; integrar os esforços públicos, privados e do terceiro setor, das esferas federal, estadual, municipal e local, para convergirem no desenvolvimento do território e, por fim, disseminar o conhecimento à população local sobre as peculiaridades e potencialidades do território.

Terluin (2003) afirma que o foco do desenvolvimento endógeno, um dos eixos do campo dos estudos rurais, está direcionado para o desenvolvimento local, 
constituído por impulsos locais e fundamentado em recursos do território em que os atores e as organizações públicas e privadas exercem papel fundamental. Dentre essas organizações, o autor destaca as associações e cooperativas.

Buainaim e Romeiro (2000) concluíram que a agricultura familiar amplia, em geral, princípios complexos de produção convencionando diversas culturas, entre elas a criação de animais e o cultivo de hortifrutigranjeiros para o consumo da família e comercialização, objetivando o fomento da economia de determinado local.

Chelotti e Pessôa (2011) afirmam que os modelos de desenvolvimento de sucesso, buscam a melhor distribuição de renda para pequenos agricultores e apontam os seguintes obstáculos nas experiências de sucesso: a falta da especialização de mão de obra, a organização dos produtores, a insuficiência de políticas públicas de apoio ao camponês, e a carência do conhecimento para agregar valores aos produtos.

\section{Métodos e Procedimentos}

A pesquisa é descritiva exploratória e, quanto à abordagem, é quantitativa. Para a elaboração deste trabalho, foram aplicadas 321 entrevistas estruturadas, por meio de formulários, a agricultores familiares da área de estudo no período entre 4 de fevereiro e 2 de março de 2017.

De acordo com os dados apresentados pela Empresa de Assistência Técnica e Extensão Rural (EMATER), do município de Rolim de Moura (RO) e com o Censo Agropecuário do IBGE (2006) há 2.467 agricultores familiares.

A amostra desta pesquisa compreende 321 agricultores familiares, moradores na zona rural do município de Rolim de Moura (RO), em condição de proprietário, arrendatário, com acesso temporário ou assentado a terra, que atenda ao perfil e características de agricultor familiar designado pelo IBGE, que segundo a EMATER tenha acesso às políticas públicas e programas de incentivo à agricultura familiar e que assinem o termo de consentimento livre e esclarecido.

A amostra foi determinada a partir do cálculo amostral, utilizando-se o nível de confiança de $95 \%$ e o erro amostral de $5 \%$.

Para a elaboração do questionário considerou-se a interpretação de Lastres e Cassiolato (2005) sobre as variações da interpretação de território às dimensões física, econômica, simbólica e sociopolítica.

A dimensão física buscou orientar o pesquisador sobre os recursos e práticas territoriais, apresentando perguntas como a extensão da propriedade e a suficiências de máquinas e equipamentos. A dimensão econômica norteou a coleta de dados sobre os processos de produção. A dimensão simbólica contemplou as relações culturais e de identidade e, por fim, a dimensão sociopolítica pesquisou sobre as relações sociais dos agricultores familiares.

O formulário, com um total de 51 perguntas fechadas, foi dividido em cinco partes, a saber: a primeira compreende a caracterização dos agricultores familiares do município de Rolim de Moura (RO) com sete perguntas para identificar: o perfil, o núcleo familiar, a renda, o tempo de atividade social e seu local de origem.

$\mathrm{Na}$ segunda parte, em dez perguntas os agricultores foram questionados sobre a dimensão física: o tipo de acesso à terra, a extensão da propriedade, os 
principais produtos cultivados na propriedade, as atividades agregadas e a pretensão de aquisição de máquinas, equipamentos e novas propriedades.

Na terceira parte, com a finalidade de analisar a dimensão econômica, os agricultores responderam a 15 perguntas que buscaram identificar os aspectos de produção, comercialização agrícola e suas operações.

A quarta parte visou compreender, também por meio de dez perguntas, a dimensão simbólica do agricultor com o espaço, questionando-o sobre hábitos e costumes que o identificam com o local.

A quinta parte, finalizando, apresenta nove perguntas referentes à dimensão sociopolítica, identificando o conhecimento do entrevistado acerca da identidade territorial, a participação em cooperativas e os benefícios destinados à agricultura familiar do município.

Para a validação do instrumento de pesquisa foram aplicadas 35 entrevistas entre os dias 24 de novembro e 03 de dezembro de 2016 a agricultores familiares que atendem aos critérios estabelecidos na amostra.

As demais entrevistas foram realizadas na zona rural do município de Rolim de Moura (RO), de 04 de fevereiro e 02 de março de 2017, no período diurno, na propriedade rural dos agricultores familiares.

As propriedades rurais do município de Rolim de Moura (RO) são distribuídas por meio de linhas ou travessões que dividem o município de Norte a Sulem intervalos de 4 km; tais Linhas são numeradas entre 156 e 208, sendo que a zona urbana de Rolim de Moura (RO) está localizada entre as Linhas 180 e 188.

A pesquisa concentrou-se nas Linhas: 152 Lado Norte até a altura do quilômetro 3 e Lado Sul até a altura do km 15; 168 Lado Sul até a altura do km 7; 172 Lado Norte até a altura do Km 5 e Lado Sul até a altura do Km 15; 178 Lado Sul até a altura do km 10; Linha 200 Lado Sul até a altura do km 6; Linha 208 Lado Norte até a altura do quilômetro 5 e Lado Sul até a altura do quilômetro 15 e foram aplicadas aos responsáveis pela propriedade.

Os dados da pesquisa foram tabulados e analisados no software IBM SPSS Statics por meio da correlação bivariável, utilizando-se a correlação de Pearson. As correlações foram realizadas entre as dimensões norteadoras do questionário de pesquisa: dimensão física, dimensão econômica, dimensão simbólica e dimensão sociopolítica.

Todas as variáveis foram correlacionadas com todas e o resultado foi disposto em tabelas e analisado individualmente segundo o grau de relevância tratado na revisão de literatura.

O coeficiente de Correlação de Pearson é uma medida do grau de relação linear entre duas variáveis quantitativas. Este coeficiente varia entre os valores $-1 \mathrm{e}$ 1. O valor o (zero) significa que não há relação linear, o valor 1 indica uma relação linear perfeita e o valor -1 também indica uma relação linear perfeita mas inversa, ou seja quando uma das variáveis aumenta a outra diminui. Quanto mais próximo estiver de 1 ou -1, mais forte é a associação linear entre as duas variáveis (OLIVEIRA, 2008).

\section{Resultados e Discussões}


Foram entrevistados 296 agricultores familiares do gênero masculino e 25 do gênero feminino. Do total, 11,52\% têm idade até 25 anos; $19,92 \%$ entre 26 e 35 anos; $29,59 \%$ entre 26 e 45 anos; $18,69 \%$ entre 46 e 55 anos; e $20,27 \%$ com idade superior a 56 anos.

A primeira parte da pesquisa, que caracteriza o agricultor familiar, apresentou dados relevantes quanto ao tipo de acesso à terra: $89 \%$ entrevistados são proprietários; 28 são locatários; e sete estão na condição de assentados de terras distribuídas pelo INCRA.

Quando perguntados sobre o tempo de atuação como agricultores familiares, $27,10 \%$ alegaram que atuam entre um e três anos; $41,12 \%$ entre três a seis anos; $22,12 \%$ entre sete a dez anos; $7,79 \%$ há mais de dez anos; e, 1,87\%, seis entrevistados, há menos de um ano.

Como 11,52\% dos entrevistados têm idade até 25 anos e apenas 1,87\% está na condição de agricultor familiar há menos de um ano, pressupõe-se que cerca de 10\%, embora jovens, exercem o papel no campesinato desde sua maioridade.

Dentre os entrevistados, $75,07 \%$ afirmaram que outras gerações de sua família também sobreviviam da agricultura familiar e $82,55 \%$ têm familiares que possuem propriedade rural no município, reforçando a hipótese dos hábitos, costumes, pertencimentos e valores ressaltados por Haesbaert e Limonad (2007).

Acerca da extensão da propriedade rural, 74,15\% possuem entre dois e dez alqueires paulistas de terra e a renda média mensal familiar ficou assim distribuída: $41,74 \%$ têm rendimento mensal de até um salário mínimo; 29,99\% recebem entre dois e três salários mínimos; $23,6 \%$ entre quatro e cinco salários mínimos; 2,8\% entre seis dez salários mínimos; e 1,87\% tem rendimento superior a dez salários mínimos.

Em relação à atividade remunerada, 41,74\% declararam que nenhum membro da família exerce outra atividade remunerada, portanto sobrevivem apenas da atividade agrária. Evidencia-se que a renda média mensal desses agricultores está de acordo com os dados declarados pelo último Censo Agropecuário (2006) e a divulgação do IPEA (2010), que atribuem a renda de $\mathrm{R} \$ 360,00$ per capita aos agricultores familiares.

Quanto à dependência econômica do entrevistado em relação à propriedade rural, verificou-se que $80 \%$ dos entrevistados responderam que ao menos uma das pessoas da família trabalha nas atividades da propriedade rural e que 58,26\% têm ao menos um familiar que exerce outra atividade remunerada, o que caracteriza que a família do agricultor familiar não sobrevive exclusivamente da produção e comercialização rural. 
Para finalizar a caracterização do perfil dos entrevistados é importante ressaltar a diversidade dos estados de origem, já que apenas $16 \%$ são nativos do estado de Rondônia. Dos demais, $84 \%$ são provenientes de outros estados e dentre esses 33\% são procedentes do estado do Paraná porque nos anos de 1980 houve um significativo aumento da população local em razão de imigrantes do estado do Paraná que vinham e traziam seus familiares e conhecidos em busca de novas oportunidades de trabalho.

A diversidade de origem dos entrevistados pode ser atribuída ao fato de que o estado de Rondônia seja relativamente novo, pois a lei que sancionou sua criação é datada de 22 de dezembro de 1981. Embora o estado tenha passado por ciclos migratórios que vão desde a colonização portuguesa, dos primeiros núcleos de povoamento até o início da construção de hidrelétricas na primeira década dos anos 2000.

De acordo com o arranjo das origens dos agricultores familiares entrevistados percebe-se a diversidade de culturas do território, destaca-se que muitos vieram do sul do país e mantém suas tradições, seus hábitos e seus costumes. Essas tradições contemplam festas alusivas a seu estado de origem incluindo músicas, comidas típicas, festas de padroeiros e outras manifestações artísticas.

Dentre os produtos destacados pelos entrevistados como os principais cultivados na propriedade estão café, mandioca, banana, milho, mamão e laranja, ratificando a caracterização de Januário (2012) da agricultura familiar do município.

Januário (2012) afirma que a pluriatividade é o meio utilizado pelas famílias de agricultores familiares de exercer diferentes atividades agrícolas ou não agrícolas, mas que asseguram a moradia no campo e uma ligação, inclusive produtiva, com a agricultura e a vida no espaço rural.

Quando perguntados quanto às atividades paralelas da propriedade rural, os entrevistados afirmaram que os produtos produzidos nas propriedades são, em sua maioria, queijo, produtos de panificação, mel, doces e compotas, peixes, dentre outros. A informação contribui para o entendimento da evolução histórica da economia de Rolim de Moura (RO), onde a pecuária de leite foi considerada, pelo IBGE (2010), a segunda atividade econômica do município.

A seguir, são apresentadas as correlações de Pearson ( $r$ ) das dimensões pesquisadas. A Tabela 1A e B (continuação) apresenta a correlação de Pearson da dimensão econômica com a dimensão simbólica. 
Tabela $1^{a}$. Correlação de Pearson da dimensão econômica com a dimensão simbólica

\begin{tabular}{|c|c|c|c|c|c|c|c|c|c|}
\hline & & Sim1 & $\operatorname{Sim} 2$ & Sim3 & Sim4 & Sim5 & Sim6 & $\operatorname{Sim} 7$ & Sim8 \\
\hline \multirow{3}{*}{ Econ1 } & Correlação de Pearson &,$- 171^{* *}$ &,$- 110^{*}$ &,$- 118^{*}$ &, $114^{*}$ &,$- 589^{* *}$ &,$- 289^{* *}$ &,- 061 &,- 096 \\
\hline & Sig. (2 extremidades) & ,002 & ,050 & ,034 & ,041 & , 000 & ,000 & ,275 & ,086 \\
\hline & $\mathrm{N}$ & 321 & 321 & 321 & 321 & 321 & 321 & 321 & 321 \\
\hline \multirow{3}{*}{ Econ2 } & Correlação de Pearson & ,105 & $179^{* *}$ &, $181^{* *}$ &,$- 229^{* *}$ & $229^{* *}$ & $252^{* *}$ &,$- 142^{*}$ & $182^{* *}$ \\
\hline & Sig. (2 extremidades) & ,060 & ,001 & ,001 & , 000 & ,000 & ,000 & , 011 & ,001 \\
\hline & $\mathrm{N}$ & 321 & 321 & 321 & 321 & 321 & 321 & 321 & 321 \\
\hline \multirow{3}{*}{ Econ3 } & Correlação de Pearson & ,106 &, $181^{* *}$ & $184^{* *}$ &,- 068 & $232^{* *}$ & ,092 &,$- 250^{* *}$ & $257^{* *}$ \\
\hline & Sig. (2 extremidades) & ,057 & ,001 & ,001 & ,227 & ,000 & 101 & ,000 & , 000 \\
\hline & $\mathrm{N}$ & 321 & 321 & 321 & 321 & 321 & 321 & 321 & 321 \\
\hline \multirow{3}{*}{ Econ4 } & Correlação de Pearson & 109 &,- 106 &,- 107 &, $136^{*}$ &, $122^{*}$ &,- 088 & ,002 & $197^{* *}$ \\
\hline & Sig. (2 extremidades) & ,051 & ,057 & ,055 & ,015 & ,029 & ,116 & ,979 & , 000 \\
\hline & $\mathrm{N}$ & 321 & 321 & 321 & 321 & 321 & 321 & 321 & 321 \\
\hline \multirow{3}{*}{ Econ5 } & Correlação de Pearson &,$- 218^{* *}$ &, $212^{* *}$ &, $215^{* *}$ &,$- 180^{* *}$ &,$- 113^{*}$ &, $117^{*}$ & ,091 &, $112^{*}$ \\
\hline & Sig. (2 extremidades) &, 000 & ,000 & , 000 & ,001 & ,042 & ,036 & , 103 & , 044 \\
\hline & $\mathrm{N}$ & 321 & 321 & 321 & 321 & 321 & 321 & 321 & 321 \\
\hline
\end{tabular}


Edson Aparecida Araujo Querido Oliveira, Maria Antonia Fernandes Nabarro de Oliveira Benati, Marcela Barbosa de Moraes

Tabela 1B. Correlação de Pearson da dimensão econômica com a dimensão simbólica

\begin{tabular}{|c|c|c|c|c|c|c|c|c|c|}
\hline & & Sim1 & Sim2 & $\operatorname{Sim} 3$ & Sim4 & Sim5 & $\operatorname{Sim} 6$ & Sim7 & Sim8 \\
\hline \multirow{3}{*}{ Econ6 } & Correlação de Pearson & ,035 &,- 041 &,- 059 &,$- 244^{* *}$ &, $216^{* *}$ & $194^{* *}$ &, $260^{* *}$ &,$- 134^{*}$ \\
\hline & Sig. (2 extremidades) &, 529 & ,464 & ,294 & ,000 & ,000 & ,000 & , 000 & ,016 \\
\hline & $\mathrm{N}$ & 321 & 321 & 321 & 321 & 321 & 321 & 321 & 321 \\
\hline \multirow{3}{*}{ Econ7 } & Correlação de Pearson &, $202^{* *}$ &,$- 197^{* *}$ &,$- 199^{* *}$ & ,006 &, $225^{* *}$ &,- 097 & $157^{* *}$ &,- 071 \\
\hline & Sig. (2 extremidades) & ,000 & , 000 & ,000 & ,919 & , 000 & ,084 & ,005 & ,207 \\
\hline & $\mathrm{N}$ & 321 & 321 & 321 & 321 & 321 & 321 & 321 & 321 \\
\hline \multirow{3}{*}{ Econ8 } & Correlação de Pearson &, $167^{* *}$ & ,059 & ,031 &,$- 328^{* *}$ & ,023 & ,053 &,- 079 & ,003 \\
\hline & Sig. (2 extremidades) & ,003 & ,290 &, 585 & ,000 & ,682 & 348 & 157 & 960 \\
\hline & $\mathrm{N}$ & 321 & 321 & 321 & 321 & 321 & 321 & 321 & 321 \\
\hline \multirow{3}{*}{ Econg } & Correlação de Pearson &,$- 138^{*}$ &, 003 &,- 040 &,- 040 & $315^{* *}$ & ,026 &, $140^{*}$ &, 003 \\
\hline & Sig. (2 extremidades) & 013 & ,954 & ,471 & ,471 & ,000 & ,646 & , 012 & ,957 \\
\hline & $\mathrm{N}$ & 321 & 321 & 321 & 321 & 321 & 321 & 321 & 321 \\
\hline \multirow{3}{*}{ Econ10 } & Correlação de Pearson &,- 042 &,- 016 &,- 047 &,$- 356^{* *}$ &,- 050 &,- 016 & ,025 &,$- 258^{* *}$ \\
\hline & Sig. (2 extremidades) & ,457 &, 772 & ,405 &, 000 &, 370 &, 777 & ,656 &, 000 \\
\hline & $\mathrm{N}$ & 321 & 321 & 321 & 321 & 321 & 321 & 321 & 321 \\
\hline \multirow{3}{*}{ Econ11 } & Correlação de Pearson &,- 092 &,$- 207^{* *}$ &,$- 167^{* *}$ &,$- 194^{* *}$ &,$- 174^{* *}$ &, $131^{*}$ &,- 012 &,$- 128^{*}$ \\
\hline & Sig. (2 extremidades) & ,100 &, 000 &, 003 & ,000 & ,002 & 019 & 832 & ,022 \\
\hline & $\mathrm{N}$ & 321 & 321 & 321 & 321 & 321 & 321 & 321 & 321 \\
\hline \multirow{3}{*}{ Econ12 } & Correlação de Pearson &,- 087 & ,092 & , 040 &, $117^{*}$ & , 075 & , 084 &,- 041 & ,063 \\
\hline & Sig. (2 extremidades) & ,119 & ,099 & , 471 & ,037 & ,180 & ,135 & ,469 & ,257 \\
\hline & $\mathrm{N}$ & 321 & 321 & 321 & 321 & 321 & 321 & 321 & 321 \\
\hline \multirow{3}{*}{ Econ13 } & Correlação de Pearson &,$- 118^{*}$ & $156^{* *}$ &, $115^{*}$ & $150^{* *}$ & ,053 &,- 049 &, $142^{*}$ &, $187^{* *}$ \\
\hline & Sig. (2 extremidades) &, 035 &, 005 & ,040 & ,007 &, 346 &, 383 & ,011 &, 001 \\
\hline & $\mathrm{N}$ & 321 & 321 & 321 & 321 & 321 & 321 & 321 & 321 \\
\hline \multirow{3}{*}{ Econ14 } & Correlação de Pearson & ,090 &,- 082 &,- 103 &,$- 314^{* *}$ &,$- 112^{*}$ &,$- 124^{*}$ &,- 099 &, $169^{* *}$ \\
\hline & Sig. (2 extremidades) & ,107 & , 143 & ,065 & ,000 & ,046 &, 026 & ,076 & ,002 \\
\hline & $\mathrm{N}$ & 321 & 321 & 321 & 321 & 321 & 321 & 321 & 321 \\
\hline \multirow{3}{*}{ Econ15 } & Correlação de Pearson &,- 071 &,$- 112^{*}$ &,- 082 &,- 105 & $263^{* *}$ &,$- 148^{* *}$ & ,007 &,$- 178^{* *}$ \\
\hline & Sig. (2 extremidades) & ,207 &, 046 & ,141 & ,061 &, 000 &, 008 & 894 & ,001 \\
\hline & $\mathrm{N}$ & 321 & 321 & 321 & 321 & 321 & 321 & 321 & 321 \\
\hline
\end{tabular}

Dentre as correlações estatisticamente significativas consideradas por apresentarem um número maior entre cada série, apresentadas na Tabela1, com grifo amarelo, destaca-se que à medida que o número de entrevistados que produzem apenas para o consumo (Econ1) aumenta, diminui o quantitativo de entrevistados que afirmam que outras pessoas de sua família possuem propriedades de agricultura familiar no município (Sim5), apresentando ( $r$ ) = -,589.

A comparação das correlações aponta que os agricultores que afirmam que um maior número de produção de produtos agrícolas poderia ser absorvido pela comunidade (Econ15), já que ocorre correlação favorável com a variável outras pessoas da sua família possuem propriedades de agricultura familiar no município (Sim5). 
Pressupõe-se, portanto, que os agricultores que produzem maiores quantidades e escoam sua produção por meio de vendas no mercado local, regional (Econ3) ou estadual (Econ4), ou ainda que entregam seus produtos ao PAA (Econ6), são aqueles que têm parentesco no município (Sim5). Essa relação pode ser explicada pelo fortalecimento da produção advindo das relações entre os atores sociais.

A correlação também pressupõe que aumentando o número de entrevistados que apontam que a produção de suas propriedades rurais é diversificada (Econ5), diminui o número de entrevistados que mantêm hábitos ou costumes herdados do seu local de origem (Sim4) e afirmam que outras pessoas da sua família possuem propriedades de agricultura familiar no município (Sim5).

Assim, pode-se afirmar que as propriedades de agricultura familiar cuja característica é de arranjo institucional, formada por propriedades de parentesco, têm pouca diversidade de produtos ou, ainda, inexpressível pluriatividade.

A correlação demonstra que aumentando o número de entrevistados que afirmam que os produtos produzidos na zona rural do município são suficientes para atender à população local (Econ10), diminui o número de entrevistados que afirmam manter hábitos ou costumes herdados do seu local de origem (Sim4), e que afirmam se reunir com outras famílias da comunidade (Sim8).

O município de Rolim de Moura possui uma peculiaridade: todos os dias tem feira-livre onde são comercializados produtos como frutas, verduras, legumes, peixes, queijos, polpas de frutas, doces e compotas, pães, dentre outros. As feiras acontecem em lugares alternados, previamente estabelecidos, no período noturno, e fazem parte da cultura local, além de contribuir para que os agricultores comercializem seus produtos.

As feiras livres iniciaram suas atividades na década de 1980 quando o comércio local ainda não era suficiente para atender a demanda da população e, de acordo com os agricultores familiares, comercializavam apenas verduras e legumes. Atualmente há barracas de pastéis, crepes, açaí e vatapá atraem a população e fomentam o movimento das feiras-livres, que têm um valor simbólico para os moradores do município.

Comparando-se a correlação de Pearson da dimensão simbólica com a dimensão econômica e demonstra em suas correlações mais significativas que:

- Aumentando o número de entrevistados que alegam participar de festividades do município nos últimos dois anos (Sim1), diminui o número de entrevistados que afirmam que a produção é diversificada (Econ5), apresentando $(r)=-, 218$;

- Aumentando o número de entrevistados que afirmam que participam ativamente como membro organizador de festividades culturais do município (Sim2), diminui o número de entrevistados que afirmam que em determinadas épocas do ano é inevitável a entrada de produtos de outras regiões devido à escassez dos produtos locais em razão da entressafra (Econ11), apresentando $(r)=-, 207$;

- Aumentando o número de entrevistados que afirmam que outras pessoas da sua família possuem propriedades de agricultura familiar no município de Rolim de Moura (Sim5) e os entrevistados que afirmam que 
sua propriedade rural é herança de família (Sim6), diminui o número de entrevistados que afirmam que produzem apenas para o consumo (Econ1), apresentando (r) =-,589 e -,289;

Acerca da dimensão simbólica é possível identificar que os entrevistados mantêm hábitos e costumes herdados de seu local de origem (Sim4), participam de festividades do município (Sim1) ou participam ativamente como membro organizador de festividades do território (Sim2).

Haesbaert (2014) afirma que o território também é interpretado do ponto de vista de suas dimensões simbólicas e afetivas, como a questão do pertencimento e a formação de processos identitários. Declara que o território vai além da compreensão do domínio e poder, focando também a perspectiva da dimensão simbólica e identitária, visão que se apoia na observância do espaço e o seu caráter de identidade social.

Percebe-se, porém, que para esses agricultores familiares a produção da propriedade rural não é diversificada (Econ5), ao mesmo tempo que declaram que há insuficiência dos produtos produzidos nas propriedades da agricultura familiar (Física1) para atender à população local, atribuindo sentido de pouca produtividade ao território.

Diante do sentimento de apropriação dos atores sociais que afirmam que convivem em comunidade e que atuam em movimentos culturais, ou ainda participam ativamente como membro organizador de festividades culturais, é oportuno salientar que o conceito de apropriação e reapropriação, afirmado por Haesbaert (2014) na ótica dos símbolos e no processo das representações simbólicas da cultura, trazem aspectos que esclarecem as transformações presentes no cotidiano com relação às manifestações em determinados territórios, seja por circunstâncias geográficas, religiosas e econômicas.

- Aumentando o número de entrevistados que afirmam que a produção de sua propriedade rural é diversificada (Econ5), que os produtos produzidos são repassados para o PAA (Econ6), que o entrevistado faz cálculos antecipados para conhecer o preço mínimo de venda (Econ14) e que acreditam que um maior número da produção de produtos agrícolas poderia ser absorvida pela comunidade de Rolim de Moura (Econ15), diminui o número de entrevistados que afirmam que há suficiência de máquinas, equipamentos e estrutura em sua propriedade (Física1).

Para Abramovay (2006), a maioria dos produtores necessita de recursos de terceiros para desenvolver seus processos de maneira mais eficaz, rentável e sustentável. O autor afirma ainda que a ausência desses recursos, seja pela insuficiência da oferta de crédito, seja por causa das condições contratuais inadequadas, impõe restrições ao funcionamento da agricultura familiar moderna e, principalmente, à sua capacidade de manter-se competitiva em um mercado cada vez mais exigente.

A análise das correlações seguintes permite observar o comportamento dos agricultores familiares quanto à posse da terra:

- Aumentando o número de entrevistados que alegam produzir para venda para outros estados (Econ4) e que têm dificuldades para a comercialização dos produtos (Econ7), diminui o número de 
entrevistados que afirmam que é importante ser proprietário da terra (Física3); e

- Aumentando o número de entrevistados que afirmam produzir apenas para o consumo (Econ1) e que os preços de seus produtos são praticados em relação à concorrência (Econ12), diminui o número de entrevistados que afirmam que é importante adquirir novas propriedades rurais (Física5).

De acordo com Haesbaert e Limonad (2007), a condição de proprietário e os territórios distinguem-se por características materiais e imateriais, por suas relações sociais, processos de produção e cultura. As afirmações dos entrevistados indicam que não demonstram interesse em ser proprietários ou adquirir novas propriedades, embora as utilizem para o comércio e a geração de renda.

- Aumentando o número de entrevistados que apontam que têm dificuldade para a comercialização dos produtos (Econ7), diminui o número de entrevistados que afirmam participar das decisões tomadas pela cooperativa da qual participam (Pol4), e o coeficiente ( $r$ ) dessas variáveis é de -,342;

- Aumentando o número de entrevistados que sugerem que os preços de seus produtos estão de acordo com os preços praticados pela concorrência (Econ12), diminui o número de entrevistados que indicam ser filiados a uma cooperativa (Pol2), apresentando um coeficiente ( $r$ ) ,297; e

- Aumentando o número de entrevistados que apontam que produzem para vendas em comércio local ou regional (Econ3), diminui o número de entrevistados que sugerem que houve aumento de renda familiar após a parceria com cooperativas, EMATER e outros órgãos (Pol5). O coeficiente ( $r$ ) dessas variáveis é de -,342.

Terluin (2003) destaca as associações e cooperativas como foco do desenvolvimento intrínseco, constituído por impulsos locais e fundamentado em recursos do território em que os atores e as organizações públicas e privadas exercem papel fundamental.

Na cooperativa, os agricultores familiares são fortalecidos dentro de um grupo maior e têm mais condições de negociar melhores condições e preços mais justos para insumos como sementes, fertilizantes e equipamentos.

As cooperativas podem reunir produtores autônomos que compram e vendem em conjunto. A cooperativa agropecuária pode reunir, como associados, produtores autônomos que compram e vendem em conjunto. Giagnocavo (2010) afirmar que o cooperativismo é um modelo de economia solidária que procura maximizar o predomínio do fator trabalho sobre o fator capital. Isso significa que o cooperativismo é uma associação socioeconômica de pessoas.

Ressalta-se aqui a condição dos entrevistados que alegam ter feito aquisição de máquinas e equipamentos para a propriedade rural e sua contraposição àqueles que tiveram acesso às políticas públicas e programas de incentivo à agricultura familiar.

Relativamente ao trato das questões de posse de terra e identidade territorial ressalta-se a correlação favorável entre a condição de ser proprietário da 
Edson Aparecida Araujo Querido Oliveira, Maria Antonia Fernandes Nabarro de Oliveira Benati,

terra, do tamanho da propriedade rural e do conhecimento por parte dos entrevistados da identidade territorial.

Percebeu-se que dentre os entrevistados poucos têm acesso à políticas públicas ou programas de incentivo à agricultura familiar, e aqueles que têm não fizeram investimentos em máquinas e equipamentos para a propriedade rural nos últimos dois anos.

Outra questão acerca das correlações com maiores coeficientes de significância ocorre quando as variáveis indicam a filiação dos agricultores familiares e seu interesse em serem proprietários da terra. Ao aumentar o número de respondentes que alegam ser filiados em uma cooperativa, diminui o coeficiente de participantes que acham relevante serem proprietários da terra.

Quanto às correlações favoráveis com os mais relevantes coeficientes de significância, percebe-se a ligação entre o aumento de renda familiar com o interesse em ser proprietário da terra; a participação das decisões tomadas pela cooperativa com a variável que mensura 0 investimento em máquinas, equipamentos e estrutura.

Em relação à participação das decisões, Sen (2010) conceitua o desenvolvimento como um processo integrado de expansão de liberdades reais que as pessoas desfrutam, que também dependem de determinantes como o arranjo social e econômico e os direitos civis.

\section{Considerações Finais}

A concepção de identidade territorial faz parte das premissas de pesquisas dos recortes geográficos e dirigem-se à capacidade explicativa de fenômenos amplos e diversificados, surgindo como resultado de uma leitura reduzida e de padrões básicos de mudanças.

Lastres e Cassiolato (2005) atribuem as seguintes dimensões aos territórios: i) física: referente aos recursos naturais e aos resultados dos usos e práticas territoriais dos grupos sociais; ii) econômica: referente à organização dos processos de produção do recorte geográfico; iii) sociopolíticas: referente às relações sociais, de domínio e de poder; iv) simbólica: referente às relações afetivas, culturais e de identidade do indivíduo ou grupo com o seu espaço; e v) cognitiva: referente às condições para geração, uso e difusão de conhecimentos. As dimensões territoriais foram discutidas neste trabalho à luz da concepção dos agricultores familiares.

Acerca das características da agricultura familiar do município de Rolim de Moura (RO), certificou-se que o último Censo Agropecuário do Instituto Brasileiro de Geografia e Estatística (IBGE, 2006) apontou a existência de 4,3 milhões de estabelecimentos de agricultores familiares no Brasil (IPEA, 2008) e indicou que no município de Rolim de Moura menos de $20 \%$ da população residem na zona rural.

A informação referente à característica dos estabelecimentos de agricultores familiares no Município é complementada pela Secretaria Municipal de Agricultura (2016), que alega haver uma área plantada de 7.870 hectares, distribuída entre os principais produtos produzidos inseridos pelos imigrantes na década de 1980: café, arroz, milho, feijão, mandioca e banana.

Verificou-se, com o presente estudo, que em sua maioria os agricultores familiares são proprietários da terra, atuam como agricultores familiares, dependem 
da renda da propriedade rural para seu sustento e têm grau de parentesco com outros agricultores familiares.

Este estudo pretendeu diagnosticar qual a contribuição da agricultura familiar como fomentadora de uma identidade territorial. Quanto à produção constatou-se que os principais produtos cultivados nas propriedades de agricultura familiar do município de Rolim de Moura são café, mandioca, banana, milho, mamão e laranja, e destacando a pluriatividade das propriedades rurais percebeu-se que são produzidos queijos, produtos de panificação, mel, doces e compotas e peixes.

Quanto à característica econômica da propriedade rural, verificou-se que $80 \%$ dos agricultores familiares afirmam que ao menos uma das pessoas da família trabalha nas atividades da propriedade e 58,26\% dos entrevistados têm ao menos um familiar que exerça outra atividade remunerada, evidenciando a dependência econômica dos agricultores familiares da propriedade rural.

Em relação ao sentido de pertença dos atores sociais, pautado na dimensão simbólica como um dos fatores que contribuem para o desenvolvimento local ao compreender que o sentido relacional desses atores sociais está relacionado a fatores sentimentais, sociais e simbólicos, percebeu-se que os agricultores familiares têm propriedades rurais no município objeto deste estudo e ao mesmo tempo afirmaram que a produção da propriedade rural é diversificada, ou seja, os arranjos institucionais que comportam propriedades rurais de parentesco têm pouca diversidade de produtos.

Evidenciou-se também, por meio da pesquisa, que quanto mais alto o envolvimento dos agricultores familiares com as premissas da dimensão simbólica, menor a participação da comercialização dos produtos em feiras, no comércio local e no comércio regional, ao ponto de os entrevistados apontarem maior dificuldade na comercialização dos produtos da propriedade rural.

Quanto ao objetivo deste estudo, de especificar os ativos e recursos territoriais da agricultura familiar de Rolim de Moura (RO) em relação à dimensão física, econômica, simbólica e sociopolítica e sua relação com o desenvolvimento territorial e regional, destaca-se que um maior número de propriedades rurais adquiridas pelos agricultores familiares pode fortalecer a identidade territorial do Município com o fomento da agricultura familiar.

Conclui-se que a agricultura familiar pode contribuir para o fomento da economia do município de Rolim de Moura (RO) e criar possibilidades de desenvolvimento local por meio das relações de pertença dos atores sociais envolvidos na atividade agrícola.

Por fim, registra-se que a presente pesquisa não teve a pretensão de esgotar o estudo e o debate dialético das informações e ideias sobre o tema, que aborda a contribuição da agricultura familiar como fomentadora de uma identidade territorial.

Ante esse cenário, outras pesquisas poderão ser realizadas no intuito de complementar e alargar os estudos aqui deduzidos, ampliando as amostras e/ ou utilizando como instrumento de coleta de dados perguntas mais abrangentes, que podem possibilitar maior e mais fidedigna leitura na identificação, aferindo com maior clareza a percepção dos sujeitos sobre a contribuição da agricultura familiar na criação da identidade territorial na cidade de Rolim de Moura (RO). 
Edson Aparecida Araujo Querido Oliveira, Maria Antonia Fernandes Nabarro de Oliveira Benati, Marcela Barbosa de Moraes

\section{REFERÊNCIAS}

ABRAMOVAY, R. Agricultura familiar e reforma agrária. Estudo da Dimensão Territorial do PPA. Brasília: CGEE, 2006.

ALBAGLI, S. Território e territorialidade. In: LAGES, V., BRAGA, C., MORELLI, G. (orgs). Territórios em movimento: cultura e identidade como estratégia de inserção competitiva. Brasília: Sebrae, 2004.

BARROS, R. P. Desigualdade de renda no Brasil. Brasília: IPEA, 2007.

BASSO, D., GIORDANO, N. D., NETO SILVA, B. O estudo de trajetórias de desenvolvimento rural: caracterização e comparação de diferentes abordagens. Revista Desenvolvimento em Questão, n. 1, jan./jun. Unijuí, 2003.

BOLIGIAN, L.; ALMEIDA, R. D. A transposição didática do conceito de território no ensino de Geografia. In: GERARDI, L. H. Ambientes: Estudos de geografia. Rio Claro: Programa de Pós-graduação em Geografia - UNESP; Associação de Geografia Teorética - AGETEO, 2003.

BRENT, Z. W. Territorial restructuring and resistance in Argentina. Journal of Peasant Studies, v. 42, n. 3-4, p. 671-694, 2015.

BRESSER-PEREIRA, L. C. O conceito histórico de desenvolvimento econômico. Texto para discussão EESP/FGV, 2006, 157.

BUAINAIM, A. M.; ROMEIRO, A. R. A agricultura familiar no Brasil: agricultura familiar e sistemas de produção. 2000. Projeto: UTF/BRA/051/BRA. Disponível em: <http://www.incra.gov.br/fao>. Acesso em: 08 de janeiro de 2016.

BUARQUE, S. C. Construindo o desenvolvimento local sustentável: metodologia de planejamento. São Paulo: Garamond, 2002.

CAMARGO, R. S.; MEDINA, G. The effects of the territorial policy on social relationships of family farmers in the Vale do Rio Vermelho citzenship territory, in Goiás, Brazil. Interações (Campo Grande), v. 17, n. 1, p. 54-65, 2016.

CANO, W. Novas determinações sobre as questões regional e urbana após 1980. Texto para Discussão, 2011.

CARNIELLO, M. F.; OLIVEIRA, E. A. A. Q. Estudos de gestão e desenvolvimento regional. Rio de Janeiro: Oficina de Livros, 2010.

CHELOTTI, M. C. Reterritorialização e identidade territorial. Sociedade \& Natureza, p. 165-180, 2010. 
CHELOTTI, M. C.; PESSÔA, V. L. S. Reterritorialização e identidade territorial: os camponeses construindo novas territorialidades na fronteira Brasil/Uruguai. 2011. Disponível em: <http://www.lagea.ig.ufu.br/biblioteca/artigos/egal2009.pdf>. Acesso em: 13 janeiro 2016.

DALLABRIDA, V. R. O desenvolvimento regional: a necessidade de novos paradigmas. Santa Cruz do Sul: Edunisc, 2000.

DALLABRIDA, V. R. A gestão societária do processo de desenvolvimento local/regional. REA-Revista de Estudos da Administração, ljuí: UNIJUÍ, ano 2, nº 3 , jul./dez. 2001.

DALLABRIDA, V. R. A gestão territorial através do diálogo e da participação. Revista Electrónica de Geografía y Ciencias Sociales. Scripta Nova, 2007, p. 11-20.

DALLABRIDA, V. R. Território e desenvolvimento sustentável: indicação geográfica da erva-mate de ervais nativos no Brasil. Informe Gepec, 2012, p. 42-59.

DALLABRIDA, V. R.; CANÇADO, A. C.; TAVARES, B. Gestão Social e Governança Territorial: Interseções e especificidades teórico-práticas. Revista de Gestão e Desenvolvimento Regional, v. 9, n. 3, p. 313-353, set-dez/2013, Taubaté, SP, Brasil

DORIA L., Identità, territorio, sviluppo. Um percorso diinter pretazione, Archiviodi Studio Urbani e Regionali, Milano, 2002, 73, pp. 119-144.

FERNANDES, B. M. Os campos da pesquisa em educação do campo: espaço e território como categorias essenciais. Brasília: Programa Nacional de Educação na Reforma Agrária, 2006.

FLORES, M. A identidade cultural do território como base de estratégias de desenvolvimento: uma visão do estado da arte. In: Territorios com Identidad Cultural. Argentina: Rimisp, 2006.

FURTADO, C. Os desafios da nova geração. Revista Econômica Política, v. 24, n. 4. São Paulo, 2004.

GAFSI, M. Permanence de l'exploitationagricolefamiliale, une approche gestionnaire. In: L'agriculture em famille: travailler, réinventer, transmettre, p. 45, 2014 .

GAIO, S.; GOUVEIA, L. O Branding Territorial: uma abordagem mercadológica à Cidade. Revista A Obra Nasce, v. 4, p. 27-38, 2007.

GIDDENS, A. Modernidade e identidade. Zahar, 2002.

GOMES, C. M. P. et al. Governança da terra e (re) territorialização da agricultura familiar: possibilidades do crédito fundiário no Brasil. In: Campo-Território: Revista 
Edson Aparecida Araujo Querido Oliveira, Maria Antonia Fernandes Nabarro de Oliveira Benati, Marcela Barbosa de Moraes

de Geografia Agrária, v. 9, n. 19, 2014. GRAEUB, B. E. et al. The state of family farms in the world. World Development, v. 87, p. 1-15, 2016.

GUILHOTO, J. et al. A importância da agricultura familiar no Brasil e em seus estados. Brasília: NEAD, 2007.

HAESBAERT, R.; LIMONAD, E. O território em tempos de globalização. Revista do Departamento de Geografia. Rio de Janeiro: UERJ, 2007, p.7-19.

HAESBAERT, R.; Identidades Territoriais. In: Manifestações da cultura do espaço. Rio de Janeiro: Eduerj, 1999. p.169-190.

HAESBAERT, R. Territórios em disputa: desafios da lógica espacial zonal na luta política. Campo-Território: Revista de Geografia Agrária. v. 9, n. 18, 2014.

HAESBAERT, R. Precarização, reclusão e "exclusão" territorial. Terra Livre, v. 2, n. 23, p. 35-51, 2015.

HELMSING, A. H. J. B. Innovative local and regional economic development initiatives in Latin America: a review. Interações, v. 7, n. 12, 2016.

HOGGART, K.; BULLER, H. Rural development: a geographical perspective. Routledge, 2015.

IBGE - INSTITUTO BRASILEIRO DE GEOGRAFIA E ESTATÍSTICA. Censo 2010.

Disponível em:

<http://cidades.ibge.gov.br/xtras/perfil.php?lang=\&codmun=110028\&search=rondon ia|rolim-de-moura>. Acesso em: 12 de janeiro de 2016.

IBGE - INSTITUTO BRASILEIRO DE GEOGRAFIA E ESTATÍSTICA. Produto Interno Bruto dos municípios 2013. Disponível em:

<http://cidades.ibge.gov.br/xtras/grafico_cidades.php?lang=\&codmun=110028\&idte $\mathrm{ma}=152 \&$ search=rondonia|rolim-de-moura|produto-interno-bruto-dos-municipios2013 $\geq$. Acesso em: 05 de janeiro de 2016.

IPEA - INSTITUTO DE PESQUISA ECONÔMICA APLICADA. Competitividade do Agrobusiness Brasileiro. Relatório Final. Programa de Estudos dos Negócios do Sistema Agroindustrial (Pensa), publicado em CD-ROM, 4º vol., julho de 2008.

IPEA - INSTITUTO DE PESQUISA ECONÔMICA APLICADA. Estrutura produtiva avançada e regionalmente integrada: diagnóstico e políticas de redução das desigualdades regionais. 5 Livro, vol. 2. Brasília: Ipea, 2010.

JANUÁRIO, M. L. Rolim de Moura: uma viagem no tempo. Rolim de Moura: D’ Press, 2012. 
LANDEL, P. A.; PECQUEUR, B. Le développement territorial: une voie innovante pour les collectivités locales?, 2016.

LANG, R.; FINK, M.; KIBLER, E. Understanding place-based entrepreneurship in rural Central Europe: a comparative institutional analysis. International Small Business Journal, v. 32, n. 2, p. 204-227, 2014.

LASTRES, H. M. M; CASSIOLATO, J. E. Glossários de arranjos e sistemas produtivos e inovativos locais (Quinta Versão). Rio de Janeiro: REDESIST - Rede de Pesquisa em Sistemas Produtivos e Inovativos Locais, 2005.

LEBOSSÉ, M. As questões de identidade em geográfica cultural: algumas concepções contemporâneas. In: CORRÊA, R. L.; ROSENDAHL, Z. (Org.) Paisagens, textos e identidade. Rio de Janeiro: UERJ, 2004. p. 157-179.

MAGNAGHI, A.La bio région urbaine: petit traité sur le territoire bien commun. France: Eterotopia, 2014.

MAROCO, J. Análise estatística com utilização do SPSS. Lisboa: Edições Sílabo, 2007.

MATEUS, M. A. A. Agricultura familiar: estudo de caso da Política do Programa de Aquisição de Alimento - PAA em duas Associações Rurais no município de Rolim de Moura/RO. Porto Velho: UNIR, 2015. Dissertação (Mestrado em Desenvolvimento Regional e Meio Ambiente). Universidade Federal de Rondônia, 2015.

MEDEIROS, M. O que faz os ricos: o outro lado da desigualdade brasileira. São Paulo: Hucitec, 2005.

MEDEIROS, C. A. Desenvolvimento econômico, heterogeneidade estrutural e distribuição de renda no Brasil. Economia e Sociedade, v. 13, n. 2, p. 169-174, 2016.

MEDINA, G.; NOVAES, E.; TEIXEIRA, S. M. Desenvolvimento local em territórios empobrecidos: possibilidades de inclusão social e produtiva de produtores rurais. Interações, v. 18, n. 1, 2017.

MORAES, A. C. R. Ideologias geográficas. São Paulo: Annablume, 2005.

NANTES, J. F. D.; SCARPELLI, M. Gestão da produção rural no agronegócio. 2. ed. São Paulo. Atlas: 2001.

NAVES, L.; MENDES, E. D. P. P. Agricultura familiar e identidade territorial: a comunidade rural Olhos D’água no município de Catalão. 2015.

OLIVEIRA, D. C. Análise de conteúdo temático-categorial: uma proposta de sistematização. Rev. Enferm. out/dez-2008, 16(4): 569-576. Rio de Janeiro: UERJ. 2008. 
Edson Aparecida Araujo Querido Oliveira, Maria Antonia Fernandes Nabarro de Oliveira Benati, Marcela Barbosa de Moraes

PECQUEUR, B. Le développement territorial: une nouvelle approche des processus de développement pour les économies du sud. France: Université Joseph Fourier, 2004.

PAULILLO, L. F. Redes de poder \& territórios produtivos. São Carlos: Rima Editora da UFSCar, 2000.

POLLICE, F. O papel da identidade territorial nos processos de desenvolvimento local. Espaço e cultura, n. 27, p. 7-24, 2010.

POLLICE, F. O papel da identidade territorial nos processos de desenvolvimento local. Espaço e Cultura, 2012.

RIBEIRO, P. T. Perspectiva territorial, regionalização e redes: uma abordagem à política de saúde da República Federativa do Brasil. Saúde e Sociedade, v. 24, n. 2, p. 403-412, 2015.

SANTOS, M. J.; PONTES, A. E. Desenvolvimento local, reforma agrária e ocupação territorial: o caso do Assentamento São Domingos dos Olhos D'água. Revista de Geografia Agrária, 2016.

SANTOS, M. A questão do meio ambiente: desafios para a construção de uma perspectiva transdisciplinar. Interfac EHS-Revista de Saúde, Meio Ambiente e Sustentabilidade, v. 1, n. 1, 2013.

SANTOS, G. E. O. Cálculo amostral: calculadora on-line. 2011. Acesso em: 08 de janeiro de 2016.

SAWAIA, B. B. Identidade: uma ideologia separatista? As artimanhas da exclusão, 2001, p.119-127.

SCHNEIDER, S. A pluriatividade da agricultura familiar. Porto Alegre: UFRGS, 2003.

SCHNEIDER, S. A abordagem territorial do desenvolvimento rural e suas articulações externas. Sociologias, p. 88-125, 2004.

SCHNEIDER, S. O papel da pluriatividade numa estratégia de desenvolvimento rural. Anais. Seminário Nacional de Desenvolvimento Rural Sustentável, 2005. Brasília: MDA: CONDRAF, 2005.

SCHNEIDER, S.; CASSOL, A. Diversidade e heterogeneidade da agricultura familiar no Brasil e algumas implicações para políticas públicas. Cadernos de Ciência \& Tecnologia, v. 31, n. 2, p. 227-263, 2014. 
SCHMITT, A.; TURATTI, M. C. M.; CARVALHO, M. C. P. de. A atualização do conceito de quilombo: identidade e território nas definições teóricas. Ambiente \& Sociedade, 2002, 5.10: p. 1-8.

SEN, A. Desenvolvimento como liberdade. São Paulo: Companhia das Letras, 2010.

TERLUIN, I. J. Differences in economic development in rural regions of advanced countries: an overview and critical analysis of theories. Journal of Rural Studies. Oxford, v. 19, p. 327-344, 2003.

VERNIÈRES, M. Dynamique territorial edu monde rural, une approche patrimoniale de la place de l'agriculture. In: Un exemple: le Larzacetses vallées (Document exploratoire, version provisoire), 2014.

VIEIRA, E. T.; SANTOS, M. J. As ferramentas quantitativas e qualitativas na análise histórica do desenvolvimento regional: o Vale do Paraíba de 1970-2000. Diálogos (Maringá), v. 17, p. 279-307, 2013.

XAVIER, T. R. et al. A relevância do capital social como elemento propulsor da articulação dos atores locais em prol do desenvolvimento regional. Revista Administração em Diálogo-RAD, v. 15, n. 1, 2014.

WANDERLEY, M. N. B. Agricultura familiar e campesinato: rupturas e continuidade. Estudos Sociedade e Agricultura, v. 1, 2013.

WOODWARD, K. Identidade e diferença: uma questão cultural. Identidade e diferença: a perspectiva dos estudos culturais. Petrópolis: Vozes, 2009.

\section{Edson Aparecida Araujo Querido Oliveira}

Doutor em Engenharia Aeronáutica e Mecânica e Pós-Doutorado em Gestão da Inovação Tecnológica pelo Instituto Tecnológico de Aeronáutica (ITA), Coordenador do Programa de Pós-Graduação em Gestão e Desenvolvimento Regional da Universidade de Taubaté (UNITAU). edsonaaqo@gmail.com

\section{Maria Antonia Fernandes Nabarro de Oliveira Benati}

Doutoranda em Desenvolvimento Regional e Meio Ambiente da Universidade Federal de Rondônia (UNIR), Mestre em Gestão e Desenvolvimento Regional pela Universidade de Taubaté (UNITAU), Professora da Faculdade São Paulo (FSP-RO).ma.benati@gmail.com

\section{Marcela Barbosa de Moraes}

Doutora em Administração pela Universidade Nove de Julho (UNINOVE), Professora e Pesquisadora do Programa de Pós-Graduação em Gestão e Desenvolvimento Regional da Universidade de Taubaté (UNITAU). marcelabmoraes@gmail.com 